nternational Journal of Forensic Science \& Pathology (IJFP)

ISSN 2332-287X

\title{
Sudden Unexpected Death Due To Glottic Oedema - Report Of Two Cases
}

Case Study

Sharija.S

Assistant Professor of Forensic Medicine, Medical College, Thiruvananthapuram, Kerala, India.

\begin{abstract}
The space between the vocal cords and the mucosa covering them is the glottis. Glottic oedema can be caused by various reasons like hypersensitivity, inflammation, infection or by mechanical obstruction. Glottic oedema causes obstruction of air passages resulting in asphyxia and causes sudden unexpected death. Glottic oedema due to hypersensitivity or inhalation of smoke in cases of burn death and endotracheal intubations will come across during autopsies. Glottic oedema by local infection resulting in death is rare. At Government Medical College, Thiruvananthapuram we had two such cases of death due to glottic oedema. In these cases glottic oedema resulted from local infection at different sites.
\end{abstract}

Key Words: Glottic Oedema; Pharyngeal Abscess; Epiglottic Abscess; Asphyxia.

\section{*Corresponding Author:}

Sharija.S,

Assistant Professor of Forensic Medicine, Medical College, Thiruvananthapuram, Kerala, India.

Tel: 009104712553074

E-mail: sharijajp@yahoo.co.in

Received: July 29, 2013

Accepted: August 23, 2013

Published: August 26, 2013

Citation: Sharija.S (2013) Sudden Unexpected Death Due To Glottic Oedema - Report of Two Cases. Int J Forensic Sci Pathol. 1(1), 1-3. doi: http:/ /dx.doi.org/10.19070/2332-287X-130001

Copyright: Sharija.S ${ }^{\odot}$ 2013. This is an open-access article distributed under the terms of the Creative Commons Attribution License, which permits unrestricted use, distribution and reproduction in any medium, provided the original author and source are credited.

\section{Introduction}

Laryngo pharynx or hypo pharynx is the area of pharynx from epiglottis to commencement of oesophagus at the level of cricoid cartilage. Epiglottis is a leaf like yellow structure with free broad upper edge situated behind the root of tongue and hyoid bone. The vocal cords are situated below the attachment of epiglottis. The space between the vocal cords is 'rima glottidis' and mucosa covering them is glottis.[1] Glottis is the area of opening to lower respiratory passages. It is the narrowest part of cavity of larynx. $[2]$

The mucous membrane is loosely attached and oedema fluid readily collects there[2] Oedema of glottic area causes obstruction of air passages resulting in asphyxia. Glottic oedema can be caused by various reasons. It can be due to hypersensitivity, simple inflammation, local infection like epiglottitis, mechanical obstruction etc.[1] During autopsy; glottic oedema due to hypersensitivity, inhalation of smoke in burn cases or endotracheal intubations are usually come across. It can also occur as a complication of endotracheal anesthesia.[3] Glottic oedema by local infection resulting in death is rare. At government Medical College, Thiru- vananthapuram we had two such cases. Both cases were brought for autopsy since they died before arriving at a diagnosis. Autopsy revealed that death was due to glottic oedema. In these cases glottic oedema resulted from local infection like pharyngeal abscess and epiglottic abscess.

\section{Case Report I}

A 28 year old moderately nourished female was treated in a local hospital with history of cough and difficulty in swallowing of three days duration. She was treated there with analgesic and antibiotic on out patient basis for next two days. Throat pain became severe and she was referred to Medical College Hospital and there she died in the casualty.

At autopsy; pharynx showed a thick walled abscess $(3 \times 2.5 \times 2 \mathrm{~cm})$ near piriform fossa. (Figure 1) Glottis including epiglottis and supraglottic area was oedematous and entry of air passage was occluded. (Figure 2) All other organs showed features of asphyxial death.

Opinion was given as death due to glottic oedema following pharyngeal abscess.

\section{Case Report II}

A 19 year old well nourished male was brought dead to casualty of Medical College Hospital with history of sudden onset of foreign body sensation in the throat following intake of tender coconut juice. He had started vomiting and was taken to hospital. He died in the casualty.

At autopsy; the upper anterior surface of epiglottis showed an abscess $(2 \times 1.5 \times 1 \mathrm{~cm})$ in the middle. Glottis including epiglottis and supraglottic area was oedematous and occluding the air passage. (Figure 3) Stomach contained a few pieces of tender coconut having no unusual smell. All organs showed features of asphyxial death.

Opinion was given as death due to glottic oedema following ab- 
Figure 1. showing a thick walled abscess involving piriform fossa and adjoining soft tissue in the case 1 (with in the circle).

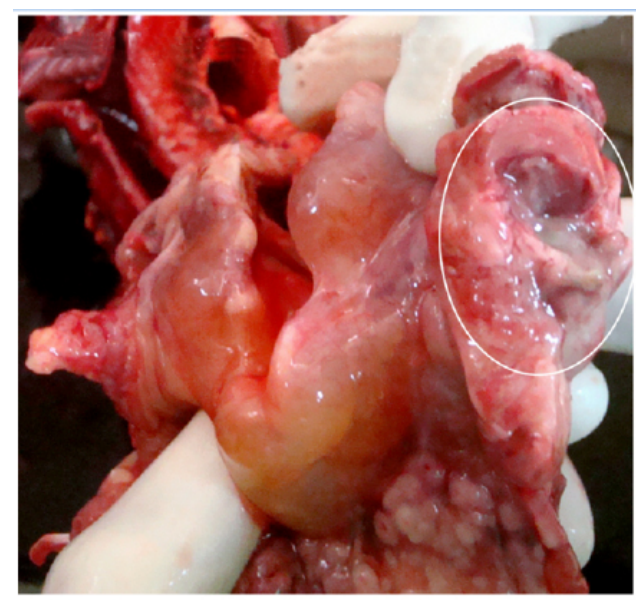

Figure 2. showing the oedematous glottis and epiglottis narrowing the opening of air passage in the case 1 (with in the circle).

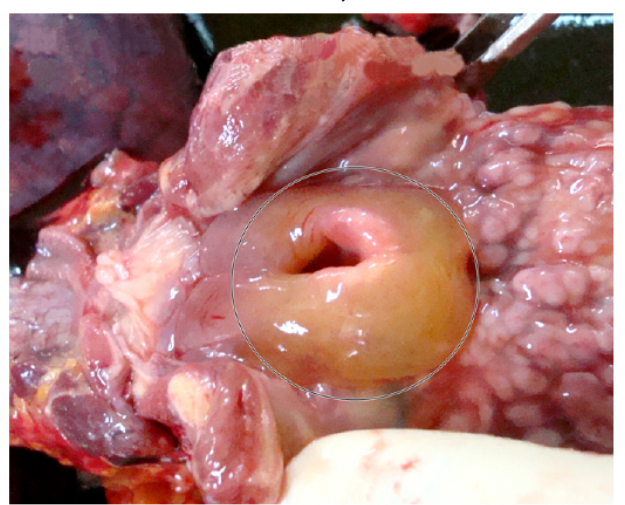

Figure 3. showing abscess in the upper anterior surface of epiglottis (pointed by arrow) with local oedema narrowing the opening of air passage (with in the circle) in the case 2

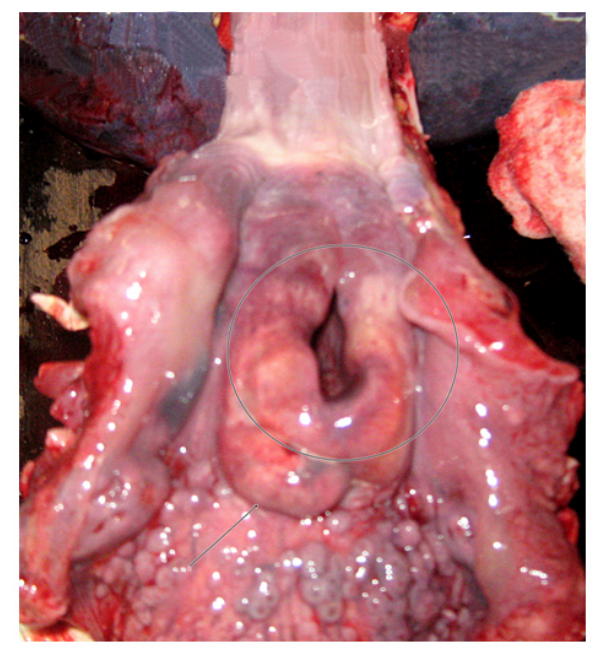

scess of epiglottis.

\section{Discussion}

Glottic oedema causes sub mucosal infiltration of serous fluid and produces a soft and firm swelling. It can be translucent if the oedema is due to transudate as in hypersensitivity reaction or opaque if due to inflammatory exudate. Fully developed oedema converts the area to a thick cushion which partly blocks the entrance of larynx. Vocal cords and subglottic area may also participate in oedema.[1]

Acute glottic oedema can occur from allergy or local inflamma- tion. [4] In local inflammation mucosa may swell due to effusion of fluid.[2] Local inflammation can be caused by streptococcus or staphylococcus. [4] Though more frequent in children, epiglottitis may also cause sudden deaths in adults.[5] Adult epiglottitis is rare. Though both pharyngeal and epiglottic abscesses are completely curable, delay in diagnosis and treatment may result in sudden and fatal respiratory obstruction. Girrish SP et al has reported four cases of adult epiglottitis causing glottic oedema. [6] Retropharyngeal abscess also causes glottic oedema. Usually both present with fever, odynophagia, dysphagia and increasing respiratory difficulty. [7] Some workers thought that adults are at less risk of airway obstruction.[8] Mayo-Smith et al emphasized that adults are at risk of airway obstruction without previous de- 
terioration. He has reported two such cases.[9]

In the present cases abscess had mild or negligible symptoms in the initial stages. Glottic oedema had resulted from exudation of fluid into that area. Finally the oedema increased and occluded the air passage. Then sudden death occurred due to asphyxia.

\section{Conclusion}

Local infection around laryngeal opening in otherwise healthy adults resulted in sudden unexpected death. Both subjects had initial negligible symptoms in the above cases. If they had been symptomatic enough and promptly diagnosed, their precious lives could have been saved. Even minor abscess or inflammations in that area should be considered and treated cautiously.

\section{Acknowledgement}

Dr. P. Rema, Professor \& Head of Forensic Medicine, Govt.
Medical College, Thiruvananthapuram, Kerala, India.

\section{References}

[1]. Rezek PR, Millard M. Autopsy Pathology. 1st edn. Charles C Thomas Publishers. Springfield. USA (1963) 216-227.

[2]. Susan Standring (Ed). Gray's Anatomy- Anatomical Basis of Clinical Practice. 9th edn. Elsevier Churchill Livingstone (2006) 638-639.

[3]. Haines AM, Powell KJ. Acute subglottic oedema of larynx as a sequel to endotracheal anaesthesia. Brit.J.Anaesth. 27 (1955) 257.

[4]. Francis E Camps (Ed). Gradwohl's legal Medicine. Bristol John Wright \& sons Ltd (1968) 249-250.

[5]. Polson CJ, Gee DJ, Knight B. The Essentials of Forensic Medicine. 4th edn. Pargamon Press. New York (1985) 557.

[6]. Gerrish SP, Jones AS. Watson DM et al. Adult Epiglottitis. Br.Med.J. 297 (7) (1987) 1183-1184

[7]. Kerr AG (Ed). Scott-Brown's Otolaryngology. 5thedn. Jaypee. Delhi (1994) 102-113.

[8]. Hawkins DB, Miller AH, Sachs GB et al. Acute Epiglottis in adults. Laryngoscope. 83 (1973) 1211-1220.

[9]. Mayo Smith MF, Hirsch PJ, Wodzinski F et al. Acute epiglottis in Adults. N Engl J Med. 314 (1986) 1133-1139. 